\title{
Perawatan Gigitan Terbuka Anteroposterior Tipe Skeletal dengan Teknik Straightwire
}

\author{
Vega Mandala, Wayan Ardhana, dan Christnawati \\ Program Studi Ortodonsia, PPDGS, Fakultas Kedokteran Gigi, Universitas Gadjah Mada \\ JI Denta No 1 Sekip Utara, Yogyakarta, Indonesia; e-mail: ancillavega@gmail.com
}

\begin{abstract}
ABSTRAK
Gigitan terbuka merupakan maloklusi yang bercirikan tidak terdapatnya tutup menutup gigi rahang atas dan bawah, dapat terjadi pada regio anterior maupun posterior dan dapat melibatkan dental maupun skeletal. Maloklusi ini memerlukan ketelitian dalam penentuan diagnosis dan perawatan untuk mendapatkan hasil perawatan yang baik dan kestabilan jangka panjang. Tujuan penulisan studi kasus ini adalah untuk menginformasikan manajemen pasien dengan gigitan terbuka tipe skeletal. Pasien pria berumur 19 tahun datang ke Klinik Ortodonsia FKG UGM dengan keluhan utama gigi depan yang tidak rata dan tidak dapat digunakan untuk menggigit. Pemeriksaan klinis menunjukkan pasien memiliki kebiasaan menelan dengan menjulurkan lidah. Pemeriksaan model studi menunjukkan maloklusi Angle kelas I dengan gigitan terbuka anterior dari regio premolar kedua kanan ke kiri sebesar 10,7 mm disertai malposisi gigi individual dan pergeseran garis tengah rahang bawah ke kiri. Pemeriksaan sefalometri menunjukkan relasi skeletal kelas II dengan retrusif bimaksila, rotasi mandibula searah jarum jam dan gigitan terbuka skeletal. Pasien menolak tindakan bedah ortognatik sehingga dilakukan perawatan ortodontik kamuflase. Perawatan diawali dengan latihan miofungsional untuk melatih cara penelanan yang benar dilanjutkan dengan perawatan ortodontik teknik straightwire dengan pencabutan empat gigi molar pertama. Penutupan gigitan terbuka menggunakan elastic box anterior. Hasil evaluasi menunjukkan pengurangan besar gigitan terbuka dari $10,7 \mathrm{~mm}$ menjadi $1,25 \mathrm{~mm}$. Kesimpulannya elastic box anterior dapat digunakan untuk mengoreksi gigitan terbuka yang etiologinya melibatkan intrusi gigi anterior.
\end{abstract}

Maj Ked Gi. Desember 2014; 21(2): 178 - 183

Kata kunci: gigitan terbuka skeletal, pencabutan empat gigi molar pertama, straightwire

ABSTRACT: Skeletal Anteroposterior Open Bite Treatment with Straight Wire Technique. Open bite is a malocclusion with characteristic no overlapping between maxillar and mandibular teeth. This malocclusion may occur in anterior or posterior region and involved dental or skeletal. This malocclusion needed precise diagnosis and treatment to get a good treatment result and long term stability. The aim of this case report was to inform management of patient with skeletal open bite. A 19 years old male came to orthodontic clinic Faculty of Dentistry Gadjah Mada University with the chief complaint anterior crowding, and anterior teeth cannot be used to bite. Clinical finding showed patient had tongue thrusting habit. Study model analysis showed class I Angle malocclusion with $10.7 \mathrm{~mm}$ anterior open bite from right second premolar to left second premolar, with individual teeth malposition and mandibular midline shifting to the left. Cephalometric finding showed class II skeletal relationship with bimaxillar retrusive, clockwise mandibular rotation and skeletal open bite. This patient refused orthognatic surgery, so he received camouflage orthodontic treatment. This treatment was started with monofunctional exercise to correct the swallowing action then continued with straight wire orthodontic treatment with four first molar extractions. Anterior box elastic was used to close the bite. Evaluation result showed open bite was decreased from $10.7 \mathrm{~mm}$ to $1.25 \mathrm{~mm}$. The conclusion was anterior box elastic could be used in open bite correction that involved anterior teeth intrusion as an etiology.

Maj Ked Gi. Desember 2014; 21(2): 178 - 183

Keywords: skeletal open bite, four first molar extraction, straight wire

\section{PENDAHULUAN}

Gigitan terbuka merupakan maloklusi yang bercirikan tidak terdapatnya tutup menutup gigi rahang atas dan bawah. Maloklusi ini terjadi pada bidang vertikal. ${ }^{1}$ Perawatan gigitan terbuka merupakan salah satu perawatan yang menarik karena beragamnya rencana perawatan yang terkait dengan perbedaan etiologi maloklusi dan kecenderungan maloklusi ini untuk relaps bahkan setelah tindakan bedah. Maloklusi ini memerlukan ketelitian diagnosis dan penentuan perawatan yang seksama untuk mencapai hasil perawatan yang baik dan kestabilan dalam jangka panjang. ${ }^{2}$ 
Gigitan terbuka dapat terjadi pada regio anterior maupun posterior dan dapat melibatkan dental maupun skeletal. Maloklusi yang bersifat dental hanya melibatkan gigi geligi saja tanpa kelainan pada hubungan rahang. Karakteristik pasien dengan gigitan terbuka tipe dental meliputi gigi anterior maksila yang proklinasi, terdapat ruang antara gigi anterior atas dan bawah karena tidak saling beroklusi, dan ada kemungkinan pasien memiliki lengkung maksila yang sempit karena posisi lidah yang lebih rendah. Pasien yang mengalami gigitan terbuka tipe skeletal dapat memiliki beberapa karasteristik seperti peningkatan tinggi wajah anterior bawah, penurunan tinggi wajah anterior atas, peningkatan tinggi wajah anterior dan penurunan tinggi wajah posterior, bidang mandibula yang curam, serta ramus dan corpus mandibula yang kecil, ${ }^{1}$ serta peningkatan sudut gonial. Pasien ini memiliki pola pertumbuhan yang tidak menguntungkan dengan tulang basal yang divergen. ${ }^{3}$

Gigitan terbuka memiliki etiologi yang bersifat multifaktorial. Maloklusi ini dapat disebabkan oleh keturunan maupun tidak. Beberapa faktor penyebab gigitan terbuka meliputi kebiasaan menghisap ibu jari yang berkepanjangan, kebiasaan tongue thrusting, obstruksi jalan nafas nasofaring yang terkait dengan kebiasaan bernafas lewat mulut, posisi lidah saat istirahat, serta faktor keturunan yang meliputi ukuran lidah yang lebih besar dari normal, dan pola pertumbuhan tulang yang abnormal. ${ }^{2,3}$ Gangguan mekanis saat erupsi baik sebelum maupun setelah gigi melewati tulang alveolar seperti ankilosis gigi, adanya penghalang pada jalan erupsi (misalnya gigi supernumerari, akar gigi atau tulang alveolar yang tidak teresorbsi), adanya tekanan dari jaringan lunak (misalnya pipi, lidah, jari) setelah gigi melewati tulang alveolar, dan kegagalan mekanisme erupsi gigi sehingga erupsi tidak mencapai seharusnya. Gigitan terbuka yang bersifat skeletal dapat disebabkan oleh rotasi maksila berlawanan arah jarum jam, rotasi mandibula searah jarum jam, kombinasi keduanya, atau adanya pertumbuhan maksila arah vertikal yang berlebihan. ${ }^{1}$
Perawatan gigitan terbuka meliputi menghilangkan penyebab gigitan terbuka, perawatan miofungsional, perawatan ortodontik, maupun koreksi bedah. Penyebab gigitan terbuka harus dihilangkan terutama bila disebabkan oleh kebiasaan yang masih aktif, dapat menggunakan habit breaker lepasan maupun cekat. Perawatan miofungsional dapat dilakukan untuk memodifikasi arah pertumbuhan rahang bila pasien masih dalam usia pertumbuhan. Alat yang dapat digunakan seperti Frankel IV atau modifikasi aktivator dengan peninggi gigitan posterior untuk intrusi posterior dalam perawatan gigitan terbuka anterior, atau vertical pull headgear dan chin cup untuk memodifikasi pertumbuhan vertikal maksila yang berlebih dan rotasi mandibula searah jarum jam. Perawatan ortodontik dapat dilakukan dengan alat cekat untuk mengekstrusi gigi anterior atau mengintrusi molar. Pada gigitan terbuka skeletal yang berat dapat dilakukan tidakan bedah ortognatik. ${ }^{1,4}$ Tujuan penulisan studi kasus ini adalah untuk menginformasikan manajemen pasien dengan gigitan terbuka tipe skeletal. Pasien telah memberikan persetujuan tertulis perawatan dan publikasi ilmiah kasusnya secara lisan

\section{METODE}

Pasien pria berumur 19 tahun datang ke Klinik Ortodonsia FKG UGM dengan keluhan utama gigi depan yang tidak rata dan tidak dapat digunakan untuk menggigit (Gambar 1). Pemeriksaan klinis menunjukkan pasien memiliki kebiasaan menelan dengan menjulurkan lidah dan mengunyah satu sisi pada sisi kiri. Pasien memiliki riwayat minum susu dengan dot sampai ke pangkal dot dan menggigit ujung dot pada geraham sampai umur 6 tahun. Riwayat keluarga yang berhubungan dengan keluhan pasien tidak ditemukan. Pemeriksaan gigi geligi menunjukkan terdapat tambalan pada gigi molar pertama atas dan molar pertama kiri bawah, sedangkan molar pertama kanan bawah karies besar. Pemeriksaan model studi menunjukkan maloklusi Angle kelas I dengan gigitan terbuka anterior dari regio premolar kedua kanan ke kiri sebesar $10,7 \mathrm{~mm}$ disertai malposisi gigi individual dan pergeseran garis tengah rahang bawah ke kiri 

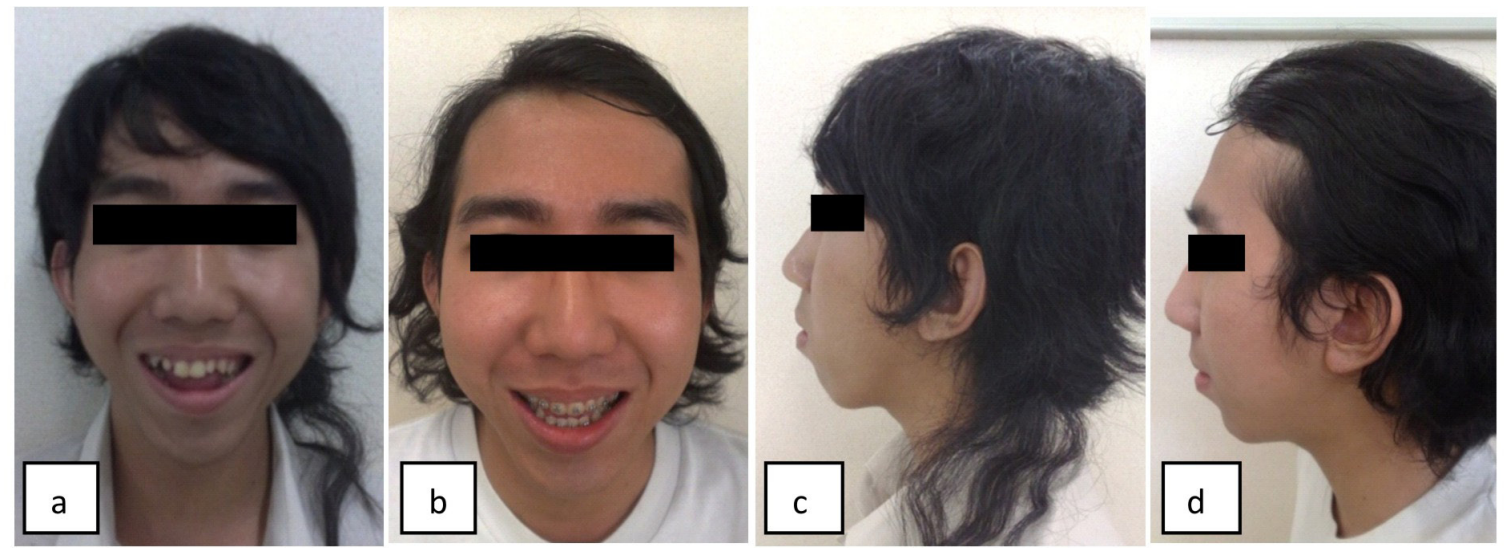

Gambar 1. Foto pasien sebelum perawatan:(a) tampak depan, saat tersenyum gigi berjejal dan gigi bawah tidak terlihat dan (c) tampak samping, profil cembung; setelah perawatan: (b) tampak depan, gigi rata dan gigi bawah terlihat saat tersenyum, dan (d) tampak samping, kecembungan berkurang dan penutupan mulut lebih alami.

sebesar 2,1 mm. Pemeriksaan sefalometri lateral menunjukkan relasi skeletal kelas II dengan retrusif bimaksila, dan rotasi mandibula searah jarum jam (Tabel 1, Gambar 2). Pemeriksaan sefalometri frontal menunjukkan open bite skeletal dengan peningkatan proporsi tinggi wajah atas, penurunan proporsi anterior maksila dan mandibula, tepi inferior mandibula yang memanjang dan sudut condylar yang membesar. Pemeriksaan ronsen panoramik menunjukkan benih gigi molar ketiga atas dengan posisi normal, dan benih gigi molar ketiga bawah dengan posisi mesioanguler.

Pasien menolak tindakan bedah ortognatik sehingga dilakukan perawatan ortodontik kamuflase. Perawatan diawali dengan latihan miofungsional untuk melatih cara penelanan yang benar dengan menyentuhkan lidah pada langitlangit saat menelan dan menghilangkan kebiasaan mengunyah satu sisi. Latihan penelanan dilakukan dengan menggunakan karet elastik yang diletakkan pada ujung lidah dan ditahan pada langit-langit saat menelan. Perawatan dilanjutkan dengan perawatan ortodontik teknik straightwire dengan braket Roth slot 0,022 " dengan pencabutan empat gigi molar pertama. Pencabutan empat molar pertama dipilih karena lebih menguntungkan untuk koreksi gigitan terbuka dan mengurangi dimensi vertikal dibandingkan dengan melakukan intrusi pada regio molar selain itu keempat molar pertama telah mengalami kerusakan. Perawatan diawali dengan levellling menggunakan kawat busur nikel titanium
0,012", 0,014", dilanjutkan 0,016" secara berurutan. Penutupan gigitan terbuka menggunakan elastic box anterior menggunakan karet elastik 3/8" 2 oz yang digunakan saat tidur. Hasil evaluasi menunjukkan dengan pencabutan empat molar pertama gigitan terbuka berkurang sebesar $0,9 \mathrm{~mm}$, setelah proses leveling gigitan terbuka berkurang menjadi $6,7 \mathrm{~mm}$. Penggunaan elastic box anterior setelah proses leveling dapat mengurangi gigitan terbuka menjadi $1,25 \mathrm{~mm}$ (Gambar 3). Pemeriksaan sefalometri pada saat evaluasi menunjukkan terjadinya rotasi mandibula berlawanan arah jarum jam (Tabel 1).

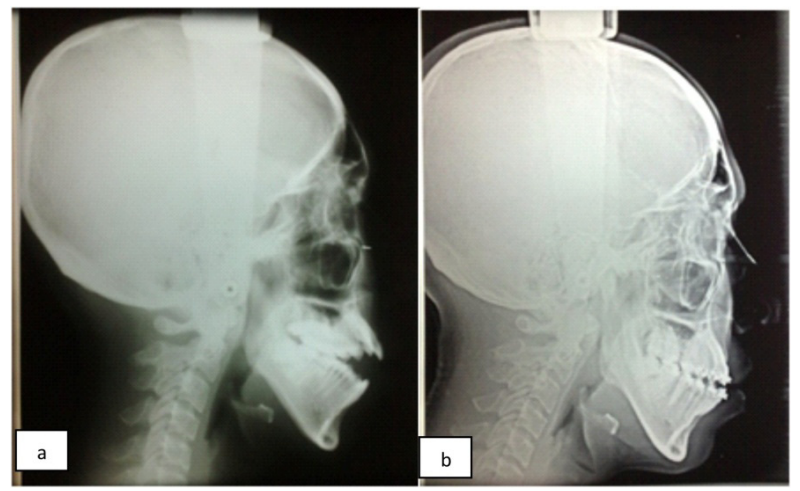

Gambar 2. Sefalometri lateral sebelum perawatan (a), terlihat gigitan terbuka regio anterior mencapai posterior dan sesudah perawatan (b), terlihat gigitan terbuka sudah berkurang.

Perawatan selanjutnya dilakukan dengan menggunakan kawat busur rektangular stainless steel 0,016"x0,022" untuk retraksi anterior bawah dan penutupan sisa ruang. Perbaikan interdigitasi 
Tabel 1. Analisis sefalometri Steiner sebelum dan sesudah perawatan.

\begin{tabular}{llccc}
\hline No & Analisis skeletal & Normal & Sebelum perawatan & Sesudah perawatan \\
\hline 1. & SNA & $82^{\circ}$ & $78^{\circ}$ & $78^{\circ}$ \\
2. & SNB & $80^{\circ}$ & $71^{\circ}$ & $73^{\circ}$ \\
3. & ANB & $2^{\circ}$ & $7^{\circ}$ & $5^{\circ}$ \\
4. & Go Gn-SN & $32^{\circ}$ & $60^{\circ}$ & $57^{\circ}$ \\
5. & Sudut bidang oklusal-SN & $14^{\circ}$ & $31^{\circ}$ & $26^{\circ}$ \\
6. & Jarak I atas-NA & $4 \mathrm{~mm}$ & $8 \mathrm{~mm}$ & $5 \mathrm{~mm}$ \\
7. & Sudut I atas-NA & $22^{\circ}$ & $25^{\circ}$ & $15^{\circ}$ \\
8. & Jarak I bawah-NB & $4 \mathrm{~mm}$ & $13 \mathrm{~mm}$ & $14 \mathrm{~mm}$ \\
9. & Sudut I bawah-NB & $25^{\circ}$ & $41^{\circ}$ & $35^{\circ}$ \\
10. & Sudut inter I & $131^{\circ}$ & $107^{\circ}$ & $125^{\circ}$ \\
\hline
\end{tabular}
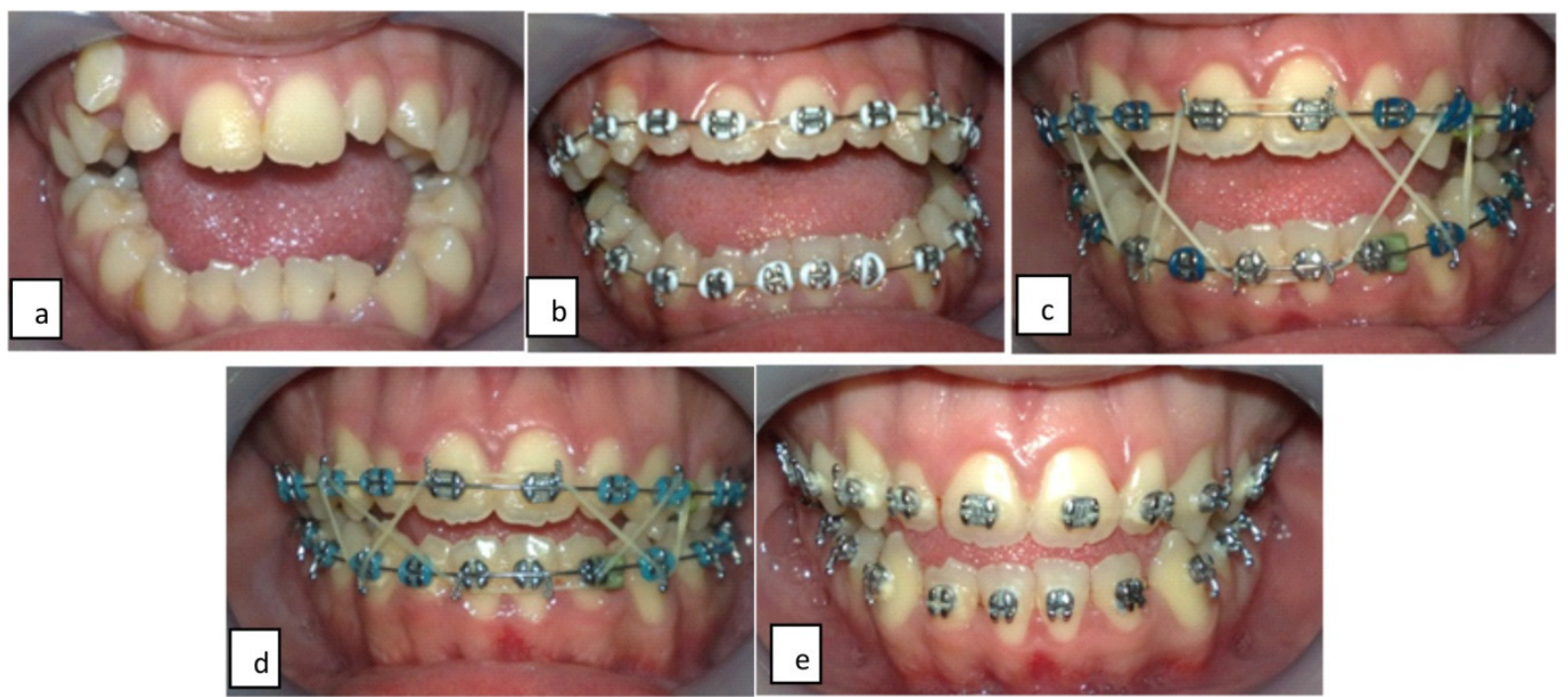

Gambar 3. Foto intra oral: (a) sebelum perawatan; (b) setelah leveling, (c) sebelum pemakaian elastic box anterior; (d) setelah 2 bulan pemakaian elastic box anterior, (e) sebelum retraksi anterior bawah.

dilakukan dengan kawat busur stainless steel 0,018 "x0,025" dikombinasikan dengan elastic box posterior atau triangle posterior sesuai kebutuhan.

\section{PEMBAHASAN}

Gigitan terbuka pada kasus ini melibatkan regio anterior dan meluas mencapai regio posterior pada gigi premolar kedua. Gigitan terbuka ini tidak hanya melibatkan gigi geligi namun juga melibatkan kelainan pada tulang. Pasien ini mengalami pertumbuhan mandibula yang berlebihan kearah bawah dan belakang membentuk tipe profil wajah hiperdivergen dengan kelainan morfologi mandibula yaitu tepi inferior yang memanjang dan sudut condylar yaitu sudut pada gonion yang terlalu tumpul menunjukkan arah pertumbuhan mandibula yang terlalu vertikal. ${ }^{5}$ Pasien yang mengalami gigitan terbuka tipe skeletal dapat memiliki beberapa karasteristik seperti bidang mandibula yang curam, ${ }^{1}$ peningkatan sudut gonial, ${ }^{3}$ dan retrognasi mandibula. ${ }^{6}$ Pasien ini memiliki pola pertumbuhan yang tidak menguntungkan dengan tulang basal yang divergen. ${ }^{3}$

Etiologi gigitan terbuka pada kasus ini kemungkinan disebabkan oleh kebiasaan pasien mengedot sampai ke pangkal botol 
yang dilakukan sampai umur 6 tahun sehingga mengubah pertumbuhan mandibula ke bawah serta menghambat pertumbuhan vertikal maksila dan mandibula pada bagian anterior. Kebiasaan tersebut diperparah dengan adanya kebiasaan menjulurkan lidah saat menelan (tongue thrusting) sehingga gigitan terbuka tetap ada walaupun pasien sudah tidak mengedot. Posisi lidah saat berfungsi maupun saat istirahat yang terletak diantara gigi atas dan bawah menyebabkan erupsi gigi tertahan dan menahan gigitan tetap terbuka. ${ }^{2,3}$ Penurunan proporsi anterior maksila dan mandibula yaitu jarak dari insisivus maksila ke ANS dan jarak dari insisivus mandibula ke menton menunjukkan adanya tahanan erupsi gigi insisivus maksila dan mandibula. ${ }^{5}$

Perawatan gigitan terbuka kasus ini dengan melakukan pencabutan empat molar pertama untuk mengurangi besar gigitan terbuka dan memberikan ruang untuk mengoreksi malposisi gigi individual. Pencabutan premolar kedua atau molar pertama sesuai dengan indikasi dapat menyebabkan rotasi mandibula berlawanan arah jarum jam pada pasien dengan gigitan terbuka skeletal yang meluas sampai ke gigi posterior. Pencabutan dilakukan pada gigi paling anterior yang berkontak dan dinilai menghambat gerak rotasi mandibula berlawanan jarum jam. ${ }^{7}$ Selain dengan pencabutan, pengurangan gigitan terbuka dapat dilakukan dengan mengintrusi gigi molar, menggunakan penjangkaran ekstra oral seperti headgear ${ }^{8}$ atau dengan menggunakan penjangkar intra oral seperti implan tipe plat $^{9}$ maupun menggunakan kawat busur nikel titanium dengan reversed curve Spee yang dikombinasikan dengan elastik vertikal pada anterior. ${ }^{10}$

Perawatan dimulai dengan latihan miofungsional untuk melatih cara penelanan yang benar dengan meletakkan ujung lidah pada langit-langit saat menelan. Latihan miofungsional ini bertujuan untuk menghilangkan penyebab terjadinya gigitan terbuka sehingga perawatan ortodontik dapat berjalan dengan efektif dan meningkatkan kestabilan setelah perawatan. Latihan dengan menggunakan karet elastik yang diletakkan pada ujung lidah dan ditahan pada langit- langit sementara melakukan gerakan menelan. ${ }^{1}$ Selain dengan latihan ini, kebiasaan dapat dihilangkan dengan menggunakan habit breaker seperti palatal atau lingual spurs sehingga posisi istirahat lidah akan berubah secara permanen. ${ }^{3}$

Perawatan dilakukan dengan alat cekat straightwire dengan braket Roth slot 0,022", menggunakan elastic box anterior yang dipasang secara zig zag setelah proses leveling selesai. Penutupan gigitan terbuka ini menggunakan kawat busur nikel titanium untuk menambah kelentingan kawat. Penutupan gigitan terbuka dilakukan dengan mengekstrusi gigi anterior dengan mempertimbangkan hasil pemeriksaan sefalometri frontal yang menunjukkan penurunan proporsi anterior maksila dan mandibula.

Gigitan terbuka merupakan maloklusi yang memiliki tingkat relaps tinggi oleh karena itu pemakaian retainer dapat diperpanjang. Retainer yang digunakan adalah retainer Hawley yang digunakan pada siang hari dan alat fungsional dengan peninggi gigitan posterior pada malam hari. $^{2}$

\section{KESIMPULAN}

Gigitan terbuka merupakan maloklusi yang memiliki berbagai pilihan perawatan sesuai dengan diagnosis dan etiologinya, selain itu maloklusi ini juga memiliki tingkat relaps yang tinggi. Hasil perawatan dan tingkat kestabilan akan ditentukan oleh kejelian klinisi dalam menentukan dan merawat etiologi maloklusi ini. Penggunaan elastic box anterior secara zig zag dapat membantu penutupan gigitan terbuka yang etiologinya melibatkan intrusi gigi anterior.

\section{DAFTAR PUSTAKA}

1. Iyyer BS. Orthodontics, the art and science. $3^{\text {rd }}$ edition. New Delhi: Arya (MEDI) Publishing House. 2004;.236-7,415-22.

2. Lin L, Huang $G$, Chen C. Etiology and treatment modalities of anterior open bite malocclusion. J Exp Clin Med. 2013; 5(1):1-4. 
3. Artese A, Drummond S, Nascimento JM, Artese F. Criteria for diagnosing and treating anterior open bite with stability. Dental Press $\mathrm{J}$ Orthod. 2011; 16(3): 136-61.

4. Oliveira JML, Dutra ALT, Pareira CM, Toledo $\mathrm{OA}$. Etiology and treatment of anterior open bite. J Health Sci Inst. 2011; 29(2): 92-5.

5. Athanasiou AE, Meij AJWV. Posteroanterior (frontal) cephalometry. In: Athanasiou, AE. Orthodontic Cephalometry. London: MosbyWolfe; 1995. h. 141-55.

6. Shetty KD, Soni VP. Skeletal open bite: a non surgical approach, a review of different techniques. 2007. Website: http://www. dypdentaljournals.com/2007/dr.kartik\%20 shetty.pdf, diunduh pada 29 Oktober 2013.
7. Aras A. Vertical changes following orthodontic extraction treatment in skeletal open bite subjects. Eur J Orthod. 2002; 24: 407-16.

8. Abdullatif $\mathrm{H}$. A new method for correction of anterior open bite. World Journal of Orthodontics, 2001; 2(3): 232-43.

9. Otsuka Y, Matsui S, Takayanagi J, Kanegae $\mathrm{H}$. Clinical experience on a case of skeletal openbite treated with lingual bracket and skeletal anchorage system without orthognathic surgery. J Meikal Dent Med. 2007; 36(2): 217-26.

10. Li Y, Liu J, Ding Y. Nonsurgical orthodontic treatment for an adult with skeletal open bite, class III malocclusion, and posterior crossbite: a case report. Open Journal of Stomatology. 2013; 3: 241-5. 